\title{
AVALIAÇÃO DO ÍNDICE DE QUALIDADE DA ÁGUA (IQA) AS MARGENS DA RODOVIA BRASILEIRA (BR-135)
}

\section{Evaluation of water quality index (WQI) to the margins of the highway BR 135 sensing}

\author{
Geraldo de Oliveira Junior ${ }^{1}$, Edilene Betânia da Cunha Coelho Brito ${ }^{2}$, \\ Danilo Augusto Fonseca Rabelo ${ }^{3}$ e Núbia Natália de Brito ${ }^{4}$
}

Recebido em 29 de setembro de 2013; recebido para revisão em 30 de outubro de 2013; aceito em 06 de novembro de 2013; disponivel on-line em 28 de novembro de 2013.

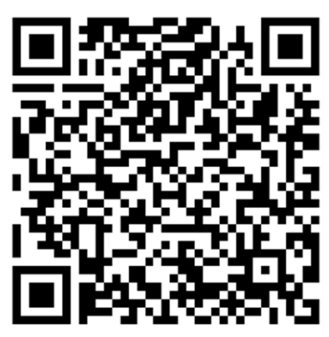

PALAVRAS CHAVES:

Recursos hídricos;

Qualidade da água;

Impacto ambiental.

KEYWORDS:

Hydric resources;

Water quality;

Environmental impact.

RESUMO: Devido à grande ênfase dada as questões relacionadas ao meio ambiente, este estudo aborda o Índice de Qualidade da Águas (IQA) às margens da rodovia BR 135. Os critérios de qualidade da água especificam concentrações e limites de alguns parâmetros que interferem na manutenção do ecossistema aquático e na proteção da saúde humana. Para o monitoramento do manancial em estudo foram utilizados os parâmetros analíticos: Oxigênio dissolvido, coliformes termotolerantes, potencial hidrogênionico $(\mathrm{pH})$, Demanda Bioquímica de Oxigênio (DBO), temperatura, nitrogênio total, fósforo total, turbidez, sólido total e óleos e graxas. Segundo a Resolução Conama 357/2005 os dados demonstraram que o manancial se enquadra na classe 2, excetuando os valores de turbidez, fósforo total e óleos e graxas.

ABSTRACT: Due to the great given emphasis the subjects related to the environment, this study approaches the Water Quality Index (WQI) to the margins of the highway BR 135. The criteria water quality specify concentrations and limits of some parameters that interfere in the maintenance of the aquatic ecosystem and in the protection of the human health. For the monitoramento of the source of living water in study the analytic parameters were used: Dissolved oxygen, thermotolerant coliforms, hydrogenionic potential $(\mathrm{pH})$, Biochemical oxygen demand (BOD), temperature, total nitrogen, total phosphorus, turbidity, total solid and oils and greases. According to the Resolution Conama 357/2005 the data demonstrated that the source of living water is framed in the class 2 , excepting the turbidity values, total phosphorus and oils and greases.

* Contato com o autor:

${ }^{1}$ e-mail: gojunior80@gmail.com (G. de Oliveira Jr. )

Tecnólogo em Química Industrial. Especialista em Gestão e Química do Meio Ambiente. Instituto de Química-IQ- Universidade Federal de Goiás

22e-mail: btbrito@gmail.com ( E. B. C. C. Brito )

Geógrafa. Especialista em Gestão e Química do Meio Ambiente. Instituto de Química-IQ- Universidade Federal de Goiás

${ }^{3}$ e-mail: danilo031981@gmail.com (D. A. F. Rabelo )

Biológo. Especialista em Gestão e Química do Meio Ambiente. Instituto de Química-IQ- Universidade Federal de Goiás

${ }^{4}$ e-mail: nubiabrito@quimica.ufg.br ( N. N. de Brito)

Profa.Dra do Instituto de Química - IQ - Universidade Federal de Goiás - UFG.

Rodovia Campus Samambaia, CP 131 CEP 74001-970 - Goiânia - Goiás, fone: 3521-1094 ramal 240. 


\section{INTRODUÇÃO}

A constante degradação da qualidade dos corpos hídricos está diretamente relacionada à poluição em diferentes formas. A ocupação e o uso desordenado do solo, associado à falta de implantação dos serviços de saneamento básico, promovem a degradação dos recursos hídricos. Segundo os dados da Pesquisa Nacional de Saneamento Básico (PNSB), apenas 38\% dos municípios brasileiros promovem a coleta dos esgotos domésticos e um percentual ainda menor, $10 \%$, realizam o tratamento dos mesmos (Silva et al., 2003).

Para entender os processos de uso e ocupação do solo, a delimitação da área de estudo é fundamental. É de consenso entre pesquisadores a definição da bacia hidrográfica como unidade de estudo, porque constitui um sistema natural bem delimitado no espaço, composto por um conjunto de terras topograficamente drenadas por um curso de água e seus afluentes, onde as interações são integradas e, assim, mais facilmente interpretadas (Santos 2004).

Os recursos hídricos sofrem ação direta das atividades desenvolvidas no entorno da bacia e se tornam indicadores potenciais das condições dos ecossistemas. Segundo Sperling (2005) a qualidade da água é resultante dos inúmeros processos que ocorrem na bacia de drenagem do corpo hídrico, estando relacionada diretamente com o uso e ocupação do solo, permitindo, muitas vezes, diagnosticar possíveis causas dos impactos ambientais sobre os recursos naturais. Dessa forma, a urbanização, as atividades agrícolas e pecuárias, o desmatamento e as queimadas, são fatores que contribuem para a diminuição da qualidade dos corpos de água.

Este estudo irá basear-se no Índice de Qualidade das Águas (IQA), criado a partir de um estudo realizado em 1970 pela "National Sanitation Foundation" dos Estados Unidos. A Cetesb o adaptou e desenvolveu o IQA - Índice de Qualidade das Águas, que incorpora 9 parâmetros considerados relevantes para a avaliação da qualidade das águas, tendo como determinante principal a utilização das mesmas para abastecimento público (Cetesb 2012).

Neste artigo serão apresentadas as interpretações dos dados das análises laboratoriais com base na Resolução do Conama $n^{\circ} 357$ para as águas superficiais, de 17 de março de 2005; Particularmente, o monitoramento da qualidade da água está voltado os corpos hídricos ao longo da BR 135 para os estados de Minas Gerais (MG) e Bahia (BA), onde a rodovia encontra-se implementada.

\section{MATERIAL E MÉTODOS}

Os pontos de amostragem foram divididos por LOTES ao longo da rodovia, pré-selecionados via geoprocessamento e as imagens foram retiradas do satélite LandSat $5 \mathrm{TM}$, interpretadas e identificando-se os cursos de maior importância regional, bem como a existência de cidades, vilas e povoados às suas margens em um raio de $\pm 10 \mathrm{~km}$ do cruzamento com a rodovia. Foram dadas preferências aos cursos que possuem assentamentos humanos à jusante da intersecção rodovia/curso hídrico dentro deste mesmo raio.

A partir da determinação do IQA é interessante avaliar individualmente $\mathrm{O}$ comportamento dos parâmetros que compõem este índice, de forma a identificar as possíveis causas dos resultados obtidos. Os parâmetros físicos, químicos e biológicos utilizados para o diagnóstico da contaminação dos rios da bacia e para a obtenção do IQA, traduzem o potencial poluidor das atividades antrópicas. Para relacionar o IQA com o uso e ocupação do solo na bacia do rio São Francisco foi levantado às áreas de uso e ocupação do solo, predominantes nas áreas de influência dos pontos de coleta, definidas em cada sub-bacia de contribuição.

A metodologia de coleta e preservação das amostras foi realizada conforme roteiro no Standard Methods for the Examination of Water and Wastewater (1998), que contém informações sobre a forma adequada do acondicionamento das mesmas, armazenamento e tempo máximo permitido entre a coleta e a análise, de forma a não comprometer a integridade da amostra e consequentemente, os resultados analíticos. Os 
parâmetros: pH, Turbidez, Temperatura e Oxigênio Dissolvido foram determinados em campo através da utilização de sonda multiparâmetros Horiba U10. As análises físico-químicas foram realizadas conforme Tabela 1.

A legislação recomenda que a comparação dos resultados laboratoriais, para cada um dos parâmetros analisados, seja feita em consonância com os valores estipulados para cada classe de uso dos corpos d'água estabelecidos na Resolução Conama 357/2005. Segundo as normas vigentes, para as águas doces superficiais, quando não há o enquadramento do curso hídrico, este deverá ser considerado como de classe de uso 2 - que é o caso para todos os mananciais amostrados.

O principal objetivo por trás da construção do IQA (Índice de Qualidade da Água) é facilitar o entendimento pelo público do estado do corpo d'água. O IQA nada mais é que a combinação por meio de formulação matemática dos parâmetros de qualidade da água medidos (ANA, 2012).

A avaliação da qualidade da água obtida pelo IQA apresenta limitações, já que este índice não analisa vários parâmetros importantes para o abastecimento público, tais como substâncias tóxicas (ex: metais tóxicos, pesticidas, compostos orgânicos), protozoários patogênicos e substâncias que interferem nas propriedades organolépticas da água. O IQA é composto por nove parâmetros com seus respectivos pesos (w), que foram fixados em função da sua importância para a conformação global da qualidade da água Tabela 2 (ANA, 2005).

\begin{tabular}{|c|c|c|c|}
\hline PARÂMETRO & UNIDADE & METODOLOGIA & EQUIPAMENTO \\
\hline Oxigênio Dissolvido (OD) & $\mathrm{mg} / \mathrm{L}$ & Medição Direta & Sonda Multiparamétrica \\
\hline Coliformes Termotolerantes & NMP & Técnica dos tubos múltiplos & Estufa, Banho Maria. \\
\hline Potencial Hidrogeniônico & - & $\begin{array}{l}\text { Medição direta- } \\
\text { potenciometria }\end{array}$ & Sonda Multiparamétrica \\
\hline Demanda Bioquímica de $\mathrm{O}_{2}$ & $\mathrm{mg} / \mathrm{L}^{-\mathrm{O}_{2}}$ & Titulometria & Estufa de incubação \\
\hline Temperatura & ${ }^{\circ} \mathrm{C}$ & Medida direta & Termômetro de Mercúrio \\
\hline Nitrogênio Total & $\mathrm{mgL}^{-1}-\mathrm{N}$ & Autoclave Espectrofotômetro & Espectrofotometria \\
\hline Fósforo Total & $\mathrm{mgL}^{-1}-\mathrm{P}$ & Autoclave Espectrofotômetro & Espectrofotometria \\
\hline Turbidez & UNT & Nefelométrico & Sonda Multiparamétrica \\
\hline óleos e graxas & $\mathrm{mg} / \mathrm{L}$ & Extração $p /$ solvente & $\begin{array}{c}\text { Extração com aparelho de } \\
\text { Soxlett }\end{array}$ \\
\hline Sólidos Totais & $\mathrm{mg} / \mathrm{L}$ & Gravimetria & Potenciométrico \\
\hline
\end{tabular}


Tabela 2: Parâmetros de Qualidade da Água no IQA e Respectivos Pesos.

\begin{tabular}{c|c}
\hline PARÂMETRO DE QUALIDADE DA ÁGUA & PESO $(\mathrm{w})$ \\
\hline Oxigênio Dissolvido & 017 \\
\hline Coliformes Termotolerantes & 015 \\
\hline Potencial hidrogenionico - pH & 012 \\
\hline Demanda Bioquímica De Oxigênio - DBO ${ }_{5-20}$ & 0,10 \\
\hline Temperatura Da Água & 0,10 \\
\hline Nitrogênio Total & 0,10 \\
\hline Fósforo Total & 0,10 \\
\hline Turbidez & 0,08 \\
\hline Sólido Total & 0,08 \\
\hline
\end{tabular}

Fonte: Agencia Nacional de Águas (2005).

\section{RESULTADOS E DISCUSSÃO}

Nos cursos hídricos analisados, apenas 3 parâmetros apresentaram valores em desacordo com a Resolução 357/2005, sendo eles : turbidez, fósforo total e óleos e graxas.

A turbidez apresentou valores acima do permitido pela legislação em um único rio Japoré (MG) tanto à jusante quanto à montante (Figura 1).

Segundo as observações em campo, o rio Japoré apresenta como principal forma de uso da terra em suas margens. A presença de moradias e um bar ocasionam poluição urbana difusa. Ambos os rios em questão à montante e à jusante, apresentam o substrato do leito com acúmulo de sedimento fino (silte e argila) e com a vegetação marginal significativamente alterada, além da presença de materiais flutuantes na água. Além disso, há utilização das águas destes para a dessedentação de animais.
O parâmetro fósforo total destaca-se pela sua importância nos sistemas biológicos, que se deve à participação em processos fundamentais do metabolismo dos seres vivos, tais como o armazenamento de energia e a estruturação da membrana celular (através dos fosfolipídios).

Em um único ponto, este parâmetro encontra-se em desacordo com a legislação para águas doces Classe 2, ambiente lêntico, no Rio Coxá (MG) a montante. Segundo Arantes e colaboradores (2013), o fósforo presente em ecossistemas aquáticos pode ser originado de fontes naturais e artificiais. As fontes naturais compreendem as rochas da bacia de drenagem que liberam fosfato para o meio através dos processos de intemperismo. Podem ser caracterizadas como fontes artificiais de fosfato os esgotos domésticos e industriais, entre outros (Figura 2). 
Turbidez

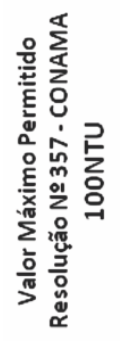

BR-135 / Lote 1

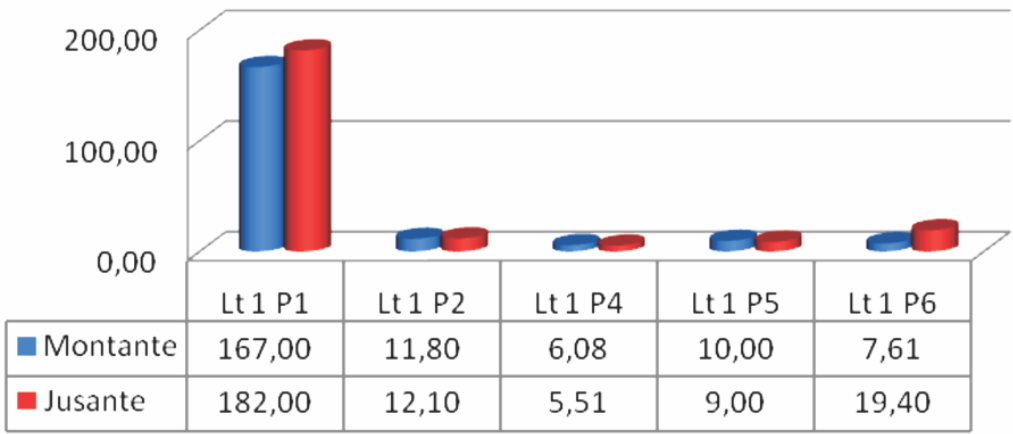

Legenda:

LT1 P1=Rio Japoré $(\mathrm{MG})$;

LT1 P2= Rio Coxá (MG);

LT1 P4= Não Identificado (BA);

LT1 P5= Não Identificado (BA);

LT1 P6= Rio Formoso (BA)

Figura 1: Análise de turbidez ao longo do curso hídrico estudado.

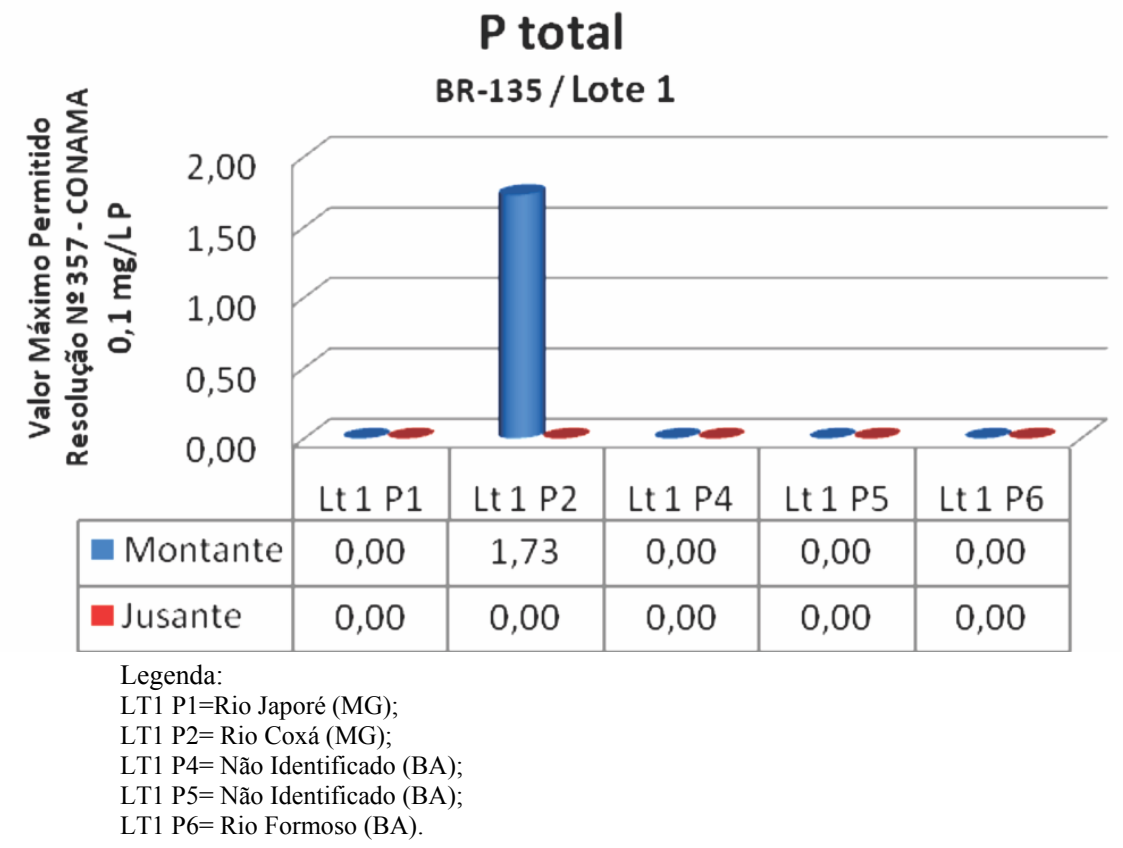

Figura 2: Análise de fósforo ao longo do curso hídrico estudado.

O parâmetro óleos e graxas são substâncias orgânicas de origem mineral, vegetal ou animal, são geralmente insolúveis em água podendo aparecer emulsionados por detergentes, álcalis ou outras substâncias químicas. Sua origem relaciona-se as atividades antropogênicas, pois raramente são encontrados em águas naturais, normalmente advêm de despejos e resíduos industriais, esgotos domésticos, efluentes de oficinas mecânicas, postos de gasolina, embarcações e dragas (Mizutori et al., 2009).

Um dos efeitos da presença de óleos e graxas é a modificação da tensão superficial dificultando as trocas gasosas, sobretudo do oxigênio causando alterações no ecossistema aquático, reduzindo o oxigênio dissolvido (OD), aumentando a Demanda Bioquímica de Oxigênio (DBO) e a Demanda Química de Oxigênio (DQO) 
(Mizutori et al., 2009). A recomendação da legislação brasileira, Conama 357/2005, é que os óleos e graxas estejam virtualmente ausentes na água doce classe 2. Ao longo dos cursos hídricos estudados (Minas Gerais a Bahia- BR 135) tanto a montante quanto a jusante foi possível detectar a presença de óleos e graxas em uma concentração variando de $0,19 \mathrm{mgL}^{-1}$ a 5,96 $\mathrm{mg}^{-1}$.

A avaliação do IQA na região estudada apresentou-se satisfatória, como mostram os gráficos seguintes (Figuras 3 e 4).

Deve-se lembrar que a poluição dos corpos de água nem sempre são causadas somente pelos esgotos domésticos e despejos industriais não tratados. Atualmente sabe-se que parte dessa poluição gerada em áreas urbanas tem origem no escoamento superficial em áreas impermeáveis (pavimentação, construções, impermeabilização, entre outros). Dessa maneira, uma parcela significativa de poluição é carregada pelo escoamento ao encontro dos corpos de água. A origem da poluição difusa é bastante diversificada, podendo vir do desgaste das ruas pelos veículos, lixo acumulado nas ruas e calçadas, atividades de construção civil, fazendas, frigoríficos, esgotos domésticos e ou industriais, resíduos de combustíveis e óleos e graxos deixadas por veículos (Santos, 2004).

\section{LOTE 1}

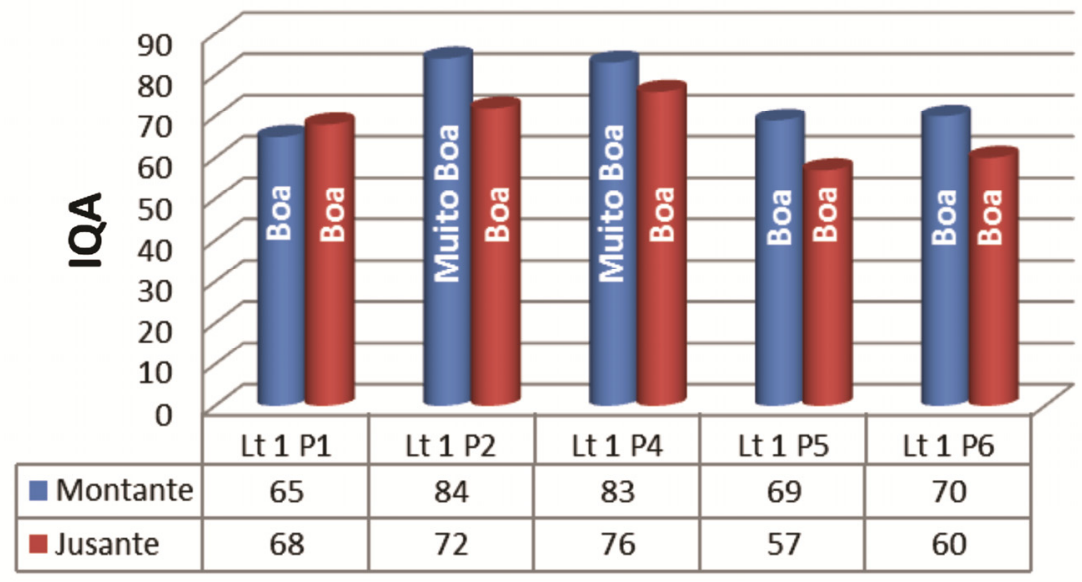

Legenda:

LT1 P1=Rio Japoré (MG);

LT1 P2= Rio Coxá (MG);

LT1 P4= Não Identificado (BA);

LT1 P5= Não Identificado (BA);

LT1 P6= Rio Formoso (BA).

Figura 3: Resultado IQA do Lote 1.

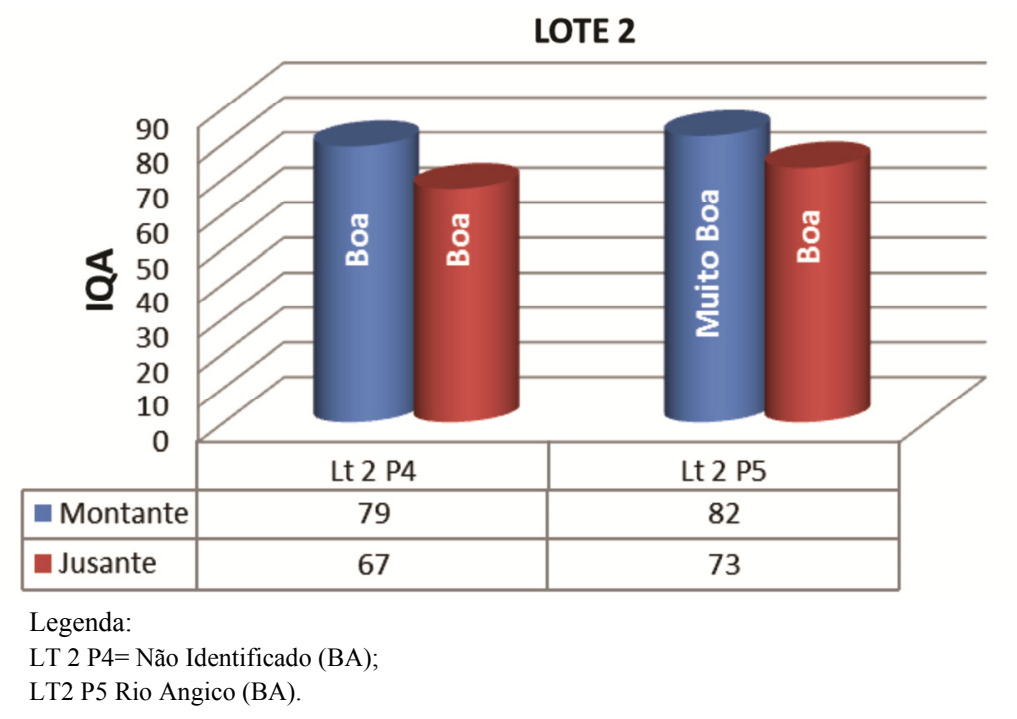

Figura 4: Resultado IQA do Lote 2. 


\section{CONCLUSÃO}

As águas superficiais do território nacional seguem classificação e padrões de qualidade determinados pela Resolução 357/2005 do Conselho Nacional do Meio Ambiente (CONAMA). Dentro desse aspecto, O IQA torna-se um bom estudo de avaliação das influencias antrópicas na região.

Entretanto, se observarmos a legislação acima referida, são analisados apenas 9 parâmetros, embora a mesma tenha sido elaborada com base em 35 parâmetros para avaliar a qualidade da água. Sugere-se, em estudos posteriores, que sejam avaliados outros índices, como os Índices de Estado Trófico (IET), Índice de Contaminação Por Tóxicos (ICT), Índice de Balneabilidade (IB) e o Índice de Proteção a Vida Aquática (IVA) para elaboração de relatórios mais detalhados. Destaca-se também a atuação de equipes multidisciplinares na elaboração destes estudos, com visões diferentes, porém integradas, com o mesmo pensamento em comum: elaborar estudo detalhado e propor soluções inovadoras, sem restrições ao progresso, porém mitigando as mais variadas formas de impactos ambientais.

\section{REFERÊNCIAS BIBLIOGRÁFICAS}

AGENCIA NACIONAL DE ÁGUAS. Indicadores de Qualidade - Índice de Qualidade das Águas. Disponível em: <http://pnqa.ana.gov.br/IndicadoresQA/IndiceQA. aspx\#_ftnref10>. Acesso em 20 de julho de 2012.

AWWA - American Water Works Association. 1998. Standard Methods for Examination of Water and WasteWater. 20th. Washington: American Public Health Association, p. 9-26.

ARANTES, A.G.S.; MENDES, A.M.; AZEREDO, W.A.; BRITO, N.N. Environmental and Statistical Analysis on Water Quality of João Leite Creek in Goiânia-GO, Brazil. International Journal of Lakes and Rivers. V.6, n.1, 2013, p.69-83.
BRASIL, CONAMA. Resolução no 357 de 17 de março de 2005 - Classificação dos corpos de água e diretrizes ambientais para o seu enquadramento e condições e padrões para o lançamento de efluentes. Brasília. 2005.

COMPANHIA DE TECNOLOGIA DE SANEAMENTO AMBIENTAL. Índice de qualidade da água - conceitos e definições. Disponível em: <http://www.cetesb.sp.gov .br>. Acesso em: 12 de agosto de 2012.

MIZUTORI, I.S.; DA SILVA, L.P.; CORRÊA, S.M.

Caracterização da qualidade das águas fluviais em meios Peri-urbanos: O caso da bacia hidrográfica do Rio Morto - RJ. Dissertação de Mestrado. Universidade do Estado do Rio de Janeiro, 2009, 162 p.

SANTOS, R.F. Planejamento ambiental: teoria e prática. São Paulo: Oficina de Textos, 2004. 184p.

SILVA, C.E.; CORADINI, M.; HOPPE, A.E; GRÄBIN T.F.; NEVES T. M. Avaliação da qualidade da água na subbacia hidrográfica do Arroio Cadena - Município de Santa Maria-RS. In: 22 CONGRESSO BRASILEIRO DE ENGENHARIA SANITÁRIA E AMBIENTAL. Joinville-SC. 2003.

SPERLING, M.V. Introdução à qualidade das águas e ao tratamento de esgotos. Princípios do tratamento biológico de águas residuárias. Belo Horizonte - MG, 6a edição, 2005. v.1, 452 p. 